\title{
The Impact of Product Planning and Design on Financial Performance with Macro Environmental Factors as an Intervening Variable: A Case Study of the Publicly-listed Construction Companies in Taiwan
}

\author{
Kuo-Wei Tsai ${ }^{1 *}$, Hsing-Chau Tseng ${ }^{2}$, Huei-Jeng Chou ${ }^{1,}$ \\ 1.Chang-Jung Christian University, Taiwan. \\ 2.Chung-Hwa Medical University.
}

*Corresponding Author Email: e37693@gmail.com

\begin{abstract}
With the rapid change of the macro environmental factors, the operations and organizations of Taiwan's overall construction industry have also been greatly affected, and in retrospect, the publicly-listed construction companies in Taiwan have often encountered the phenomenon of Bermuda Effect of Real Estate. Hence, can good product planning and design adapt to the above-mentioned adverse environmental changes? The main purposes of this study are to verify the impact of ProductPlanning-and Design on Financial Performance with Macro Environmental Factors as an intervening variable for the publicly-listed construction companies in Taiwan; besides, the directors or above of Taiwan publicly-listed construction companies as the research interview object, and this study use the database of Taiwan Economic Journal (TEJ) to obtain the company's EPS information and adopts Purposive sampling to sample the population. In addition, this study firstly establishes the SEM model and then verifies the fitting effect of the Structural model, Measurement model and Whole model.
\end{abstract}

These Findings Show that as Below

Product Planning and Design (PD) has a positive impact on Financial Performance (FP), but not significant;

Macro Environmental Factors (ME) have a positive impact on Financial Performance (FP), but not significant; and

Product Planning and Design (PD) and Macro Environmental Factors (ME), both of which have a positive interactive effect on Financial Performance (FP), but not significant. This implies that Macro Environmental Factors (ME) plays an important role in promoting Financial Performance (FP), which is also influenced by other factors.

Keywords: Product Planning and Design (PD), Macro Environmental Factors (ME), Financial Performance (FP).

\section{Introduction}


the low entry threshold and high profits. But after the peak of booming, the climate began to decline and the industry entered fierce competition. Many companies also closed down, and in this flood, there are still some construction companies standing still, and among them" Brand building is one of the major reasons for sustainable management and development; many builders began to build their "brand" for perspective of sustainable management, and brand building is a long-term process rather than an end. To create a good brand image will be for brand equity and brand extension that will have a significant effect, but also in the future enterprises must pay attention to a link.

Because the real estate industry is a relatively competitive industry, which have a great impact on domestic and foreign economic development, political stability, stock market conditions and other external factors. However, in all kinds of business cycle, there are always some construction companies cannot be affected by the business climate; regularly promoting projects; establishing a competitive advantage that makes stable profits, and gets sustainable management and survival.

Therefore, the industry found that the use of market segmentation, continuous innovation and development, which can not only establish the spirit of the brand, but also open up/ promote new markets, and in order to enhance the core competitiveness, the management can through: customer relationship maintenance and marketing strategies of market development, product differentiation, value-added-building and make-up, brand awareness popularization, and customer service etc. The globalization of trade has led to economic growth and the growing size of enterprises, just as all enterprise organizations desire to be sustainable in the market, and try to strategically introduce/ promote new products in product planning, with the aim of differentiating them from the existing product markets and anticipating to create the value of new product and market development. In the fierce competition between / among enterprises, construction companies can use different ways to enhance the competitiveness of enterprise development which the most important is the competition between product patterns.

At present, a lot of the market product brand, service, customized team; the industry itself must carefully not only choose a product to meet their needs, but also develop related products to meet the target audiences. In order to meet the customer demand preferences of different market segmentation, the design needs of enterprises in the new product planning (NPP) must be adapted to the customer needs of different market segmentation.

Therefore, the planning evaluation and product positioning of the construction product scheme have become the key success factors for the construction company's development and construction projects. In the process of development and construction projects, they have to through land analysis, planning concept of the development and compliance with the relevant building regulations/ laws, building technology rules. Besides, with a view to greatly increasing the benefits, and further increase the competitiveness and profits of construction companies, they mutual need to constantly assess and feedback to get the best solution, and do a good job of appropriate product 
planning to improve the value of residential products [1-2-3].

In addition, considering the rapid changes in the external economic and social structure of enterprises, if a little careless, the interests may be eroded, and even larger enterprises may be bankrupt suddenly. In order to take advantage of the rapidly changing environment and improve their financial performance, enterprises whether there must not only be good Product Planning and Design (PD), but also whether to recognize the changes in the Macro Environmental factors (ME), in order to ensure the sustainable operation and development of the enterprises, and the enterprise's Product Planning and Design (PD) and Macro Environmental Factors (ME) can have an interaction with Financial Performance (FP), which is the main motivation for this study.

Therefore, the Taiwan publicly-listed construction company's directors or above as the research interview object. According to the main purposes and the past relevant literature at home and abroad to extend the hypotheses, this study firstly establishes the research model and then verifies and understands the model of appropriate fitting effect. In other words, the specific purposes of this study are as follows: to verify and understand Taiwan's listed construction companies

- Whether Product Planning and Design (PD) has a significant impact on Financial Performance (FP).

- Whether Macro Environmental factor (ME) has a significant impact on Financial Performance (FP).

- Product Planning and Design (PD) and Macro Environmental Factors (ME), whether both of them have a significant interaction with Financial Performance (FP).

\section{Literature Review}

This section is to realize the correlation between the research results of past scholars and the subject of this study. From the literature review, this study develops the research hypotheses and establishes the research framework respectively. The research constructs related to the subject are briefly described below.

\section{Product Planning and Design (PD)}

The definition of Product Planning and Design" in this study is "a product designed by a construction company, in addition to the characteristics of land development, the product planners must pass through the market survey to understand the market environment, to realize customer needs and wants, to understand competitors' competitive strategies, to realize external opportunities and risks, as well as market and technological developments" and the above definition is based on a combination of the following documents.

Under the fierce competition between/ among enterprises, construction companies use different ways to enhance the development competitiveness of enterprises, the most important is the competition between products. The consumer's spending/consuming power is greatly affected by the environment, so as to stimulate consumers to consume, with the change of social structure, the values of consumers will usually be changed by the change of life-style, which will have a certain impact on the actual needs of consumers; therefore, according to the need-preferences of different group, it is 
very important to plan and design the products of different group's demand.

Product planning refers to the process by which product planners, through research survey with the purposes of understanding the market environment, realizing customer needs and wants, understand competitors' competitive strategies, realizing external opportunities and risks and market and technological developments, and developing a vision of products that can seize market opportunities and meet consumer needs, as well as strategies and tactics for implementing that vision [4-5].

Explored the two constructs of Product Planning and Design (PD), namely: (1) the quality of the project (PD1) and (2) the form of the project $(\mathrm{PD} 2)$. He [1] pointed out that the direction of product planning is comprehensive results after the analysis of relevant information to find out the pattern of the product and its possible benefits.

After reviewing the relevant building codes and risk assessment, the following projects are confirmed and until the architects conduct a precise assessment and plan the design configuration Lin \& Hong [6].

The classification of products is divided according to the target market as follows:

- Product patterns, shapes, facades and building materials.

- The Ping number of main products.

- Allocation ratio of Ping number.

- Plane layout and movement mode.

- The size and reasonable selling price of each household.

- Proportion of public facilities.

- Analysis of return on investment.
The classification of products is divided according to the architectural form as follows: Zhang [7]

- Residential: Including single-family houses, double-family houses and multi-family houses/, joint residential, thee typical features are the independent property rights per unit, low density and high privacy.

- Apartments: generally divided into two types: apartments below the fifth floor and apartments above the sixth floor. Generally, apartments below the fifth floor are called apartments, and buildings above the sixth floor are called buildings.

- Community: It is a combination of a group of houses or apartments. Domestic communities are usually assembled with buildings under the same building license. There are also public facilities, such as community roads, atrium landscaping, leisure and recreation facilities, and management facilities.

The classification of products according to their usage is as follows:

- Commercial buildings.

- Leisure products.

- Buildings for specific purposes.

- Other (plant/ factory, etc.)

Synthesis of the above and the classification of product planning and design (PD) in this study is a reference to Chen [5] classification, and have been revised.

\section{Macro Environmental Factors (ME)}

The definition of Macro Environmental Factors" in this study is "the concept of a cycle of economic fluctuations and the consideration of natural and man-made 
disasters (e.g., earthquakes, the outbreaks of COVID 19 etc." and the above definition is based on a combination of the following literature. Situ [8] pointed out that environmental factors have different degrees of impact on different industries, and in different industries, the focus and attention of enterprises should be different.

The existence of an enterprise is derived from the inputs and outputs of the environment, and is dependent on the coexistence of the external environment, so the environment is considered to be the supra-system of all organizational systems, and the enterprise organization exists in the environment and interacts with the environment.

Pearce \& Robinson [9] divided the external environment into (1) macro- environment: economic, social, political, scientific and technological, environmental ecology. (2) Industrial environment: barriers to entry, supplier bargaining power, alternatives, existing competitors. (3) Operating environment: competitors, customers, labor, suppliers, lenders.

The cognition of the environmental level, with the uncertainty of the environment and the expansion of the influence organization strategy, the environmental level also relates to the relationship from the perceptive, task and organizational, relationship so that the environmental impact is closely related to the business operation, and is more important, especially the formulation and selection of the business strategy. Chen [5] proposed the classification of the Macro Environmental Factors (ME), which are: (1) the boom cycle (ME1) and (2) natural and man-made disasters (ME2).

In the light of the above, the classification of the Macro Environmental Factors (ME) in this study is based on the classification of Chen [5].

\section{Financial Performance (FP)}

The conceptual definition of Financial Performance in this study refers to "the measurement of financial performance in terms of earnings per share (EPS) of a listed company", and the above definition is based on the following literature. Hong [10] considered performance evaluation or performance measurement to be important to the operation of an organization.

Performance is the result of performance evaluation, which expresses the results of each operation performed by the members of the organization, and is a favorable basis for the organization to engage in operational activities, resource allocation, and revise the business strategy and plan the future direction. Measurement is the most important part of control, and if it cannot be measured, it cannot be controlled, let alone managed.

Kaplan \& Norton [11] proposed a balanced score-card that connects strategies and actions from the perspectives of finance, customers, internal processes, employee learning and growth, as an organizational performance measurement system and tool. Performance indicators of performance measurement according to the measured criteria or objects can be classified as follows: (1) financial and non -financial. (2) Single indicator and a number of indicators.

(3) Financial, operational and organizational performance, and (4) organizational hierarchy classification. Lii [12] put forward financial performance indicators, operational 
performance indicators, human resources indicators, service quality performance indicators, innovative learning indicators and other five evaluation vectors, in order to recognize the integrity of enterprise process performance evaluation standards and the independence of various indicators concepts:

(1) financial performance indicators: the results of the use of enterprise resources, or named efficiency indicators.

(2) Operating performance indicators: the results of the business ability or technology of the enterprise or called efficiency indicators.

(3) Human resources indicators: the company's use of human resources to achieve results indicators. (4) Quality of service indicators: as an "attitude", is the degree of difference between customer expectations and actual perception of service, including physical, reliability, responsiveness, trust and care; and (5) innovative learning indicators: the success of the company's long-term change of environment or opportunity, on behalf of the company's ability to adapt to the future, or learning ability.

Khaliun Bibish [13] pointed out that by establishing the relationship between the Balance sheet and the Statement of Comprehensive Income, an analysis of its financial performance can determine whether the company's overall financial health is sound or not. Xie [14] pointed out that financial performance is the correct contribution to the company's operating strategy and whether its implementation and execution are contributing properly to the final operating performance. The financial statement information expresses the enterprise's cost control, asset operation management, the effect of the allocation of funds and the composition of shareholders' equity. The embodiment of financial performance can be divided into: Profitability: evaluation of enterprise profitability to reflect the net return of capital and capital appreciation, which is an important measure of enterprise performance evaluation; (2) Operational capability: it can measure the asset management ability of enterprises, which can improve the efficiency of asset use and enhance profitability; and (3) Solvency: its strength is the main index of economic strength and financial situation of enterprises, but also an important basis for measuring whether the business continues to be sound or not.

Chen [15] pointed out that there are two ways to measure financial performance. One is the Accounting-Based measure, which is based primarily on the use of corporate surpluses to reflect a company's financial position and is commonly measured by such measures as Return on Assets (ROA), Return on Equity (ROE), or Return of Sales.

Form the mentioned-above, this study measures financial performance (FP) by EPS as a measure of financial performance, and data on the financial performance of Taiwan-listed construction companies come from the 2019 Database of Taiwan Economic Journal (TEJ).

\section{Correlation between two Constructs}

The literature on the "two-two" construct-relationship among the main constructs of this study, so far, this study has not found that, in order to make the hypotheses of this study more rigorous, Purposive sampling method is adopted. In accordance with the above-mentioned research background, purposes, literature review which put forward the following three hypotheses are as follows: 


\section{Hypothesis $1\left(\mathrm{H}_{1}\right)$}

Product Planning and Design (PD) of the publicly-listed construction companies have a significant impact on Financial Performance (FP).

\section{Hypothesis $2\left(\mathrm{H}_{2}\right)$}

Macro Environmental factors (ME) has a significant impact on Financial Performance (FP). However, whether Product Planning and Design (PD) and Macro Environmental Factors (ME) can multiply or synergetic their Financial Performance at the same time is a very important topic to explore;

\section{Hypothesis $3\left(\mathrm{H}_{3}\right)$}

\section{Research Framework}

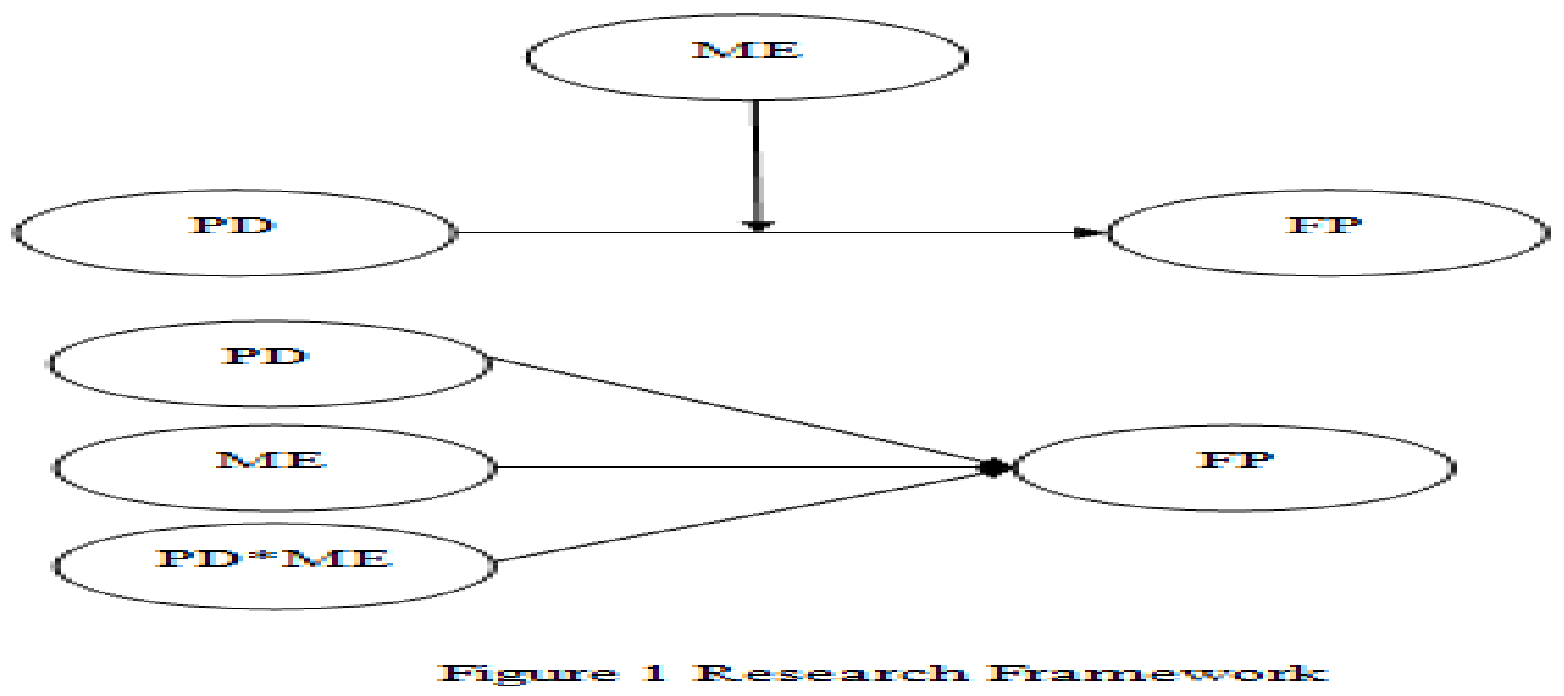

\section{Questionnaire Design}

The questionnaire design of this study is based on each observable variable and is carried out by means of "sub-measurement". The questionnaire are measured by the Likert-Scale of seven-point, giving a score of 7 to 1 according to the degree of consent and the degree of disagreement, 7 points represent extreme consent, 1 point represents extreme disagreement; the higher the degree of
As for Product Planning and Design (PD) and Macro Environmental Factors (ME) of Taiwan publicly-listed construction companies, both of which have a significant interactive effect on Financial Performance (FP), and whether this hypothesis is fully supported or not is the most critical topic in this research model.

\section{Research Method}

Based on the above research motivation, purposes and literature review, the research hypotheses are introduced and the research framework of the following research model is established, as shown in Figure 1. 
Chen (2016), which is: (1) the boom cycle $\left(\mathrm{ME}_{1}\right)$ and (2) natural and man-made disasters $\left(\mathrm{ME}_{2}\right)$ respectively, and a total of 6 questions. Regarding the measurement of Financial Performance (FP), EPS is used as a measure-tool of financial performance and is taken from the 2019 Database of Taiwan Economic Journal (TEJ).

\section{Sampling Method}

In this study, the population was sampled by using Purposive sampling. The directors or above of the publicly-listed construction companies in Taiwan are the interview objects, and the company's EPS information is obtained from the 2019 Database of Taiwan Economic Journal.

This study issued 23 expert questionnaires as pre-tests (Pilot-test), according to the experts proposed improvements to be revised, and then post-test, the official distribution of 400 questionnaires, 301 valid samples, and effective sample recovery rate of $75.25 \%$.

\section{Questionnaire Data and Measurement System}

To verify the research model proposed by this study, the linear Structural Equation Modeling (SEM) is adopted. The questionnaires are divided into Product Planning and Design (PD) and Macro Environmental Factors (ME), FP does not require a questionnaire the measurement of Financial Performance (FP) as EPS is used as a measure-tool of financial performance. In this study, three potential variables / Latent variables (PD, ME \& FP) are discussed, and each potential variable is divided into the following observable variables, and each observable variable has several questions to do the survey.

The data from the survey is then processed and the original questionnaire data file is established. As regards the construction of the measurement system of this study model, the questionnaire is designed in the form of "sub-measurement" or "double measurement", and the number of questionnaires and reference sources for the "Implicit variables" and "observable variables" of this study are shown in Table 1.

Table 1: Number of questionnaire questions on implicit and observable variables

\begin{tabular}{|c|c|c|c|}
\hline Implicit variables & Observable Variables & $\begin{array}{l}\text { Number of } \\
\text { questions }\end{array}$ & $\begin{array}{c}\text { Questionnaire } \\
\text { references }\end{array}$ \\
\hline \multirow{2}{*}{$\begin{array}{l}\text { Product Planning and } \\
\text { Design }(\mathrm{PD})\end{array}$} & Quality of the project $\left(\mathrm{PD}_{1}\right)$ & 3 & \multirow{2}{*}{ Chen (2016) } \\
\hline & Form of the project $\left(\mathrm{PD}_{2}\right)$ & 3 & \\
\hline \multirow{2}{*}{$\begin{array}{l}\text { Macro Environmental } \\
\text { factors (ME) }\end{array}$} & Boom cycle $\left(\mathrm{ME}_{1}\right)$ & 3 & \multirow[b]{2}{*}{ Chen (2016) } \\
\hline & $\begin{array}{l}\text { Natural and Man-made Disasters } \\
\qquad\left(\mathrm{ME}_{2}\right)\end{array}$ & 3 & \\
\hline $\begin{array}{l}\text { Financial Performance } \\
\qquad(\mathrm{FP})\end{array}$ & EPS (FP) & - & $\begin{array}{c}\text { Database of Taiwan } \\
\text { Economic Journal (2019) }\end{array}$ \\
\hline
\end{tabular}

\section{Linear Structure Models}

The Confirmatory Factor Analysis (CFA) is an analytical method relative to Exploratory Factor Analysis (EFA), which analyzes the validation factors between three non-observable/implicit variables such as Product Planning and Design, Macro Environmental Factors, and Financial Performance. Diamantopoulos \& Siguaw, [17] 
proposed Linear structural equation modeling (SEM), including Structural modes and Measurement model, which are effective in solving non-observable variables or hidden variables (causality between Latent Variables).

In addition, the model validated in this study consists of three parts, namely: (1) verifying the fit effect of the Measurement Model, (2) verifying the fit effect of the Structural model and (3) verifying the fit effect of Overall SEM model in line with the appropriate indicators.

\section{Results and Analysis}

\section{Analyzing fit of Measurement Model}

The factor- loading of the various non-observable / Latent / Implicit Variables and the observable / explicit variables is primarily a measure of the linear correlation between Explicit and Implicit Variables;
Fornell \& Larcker [18] proposed that the closer factor loading is to 1 , the more observable variables are to measure non-observable variables; in addition, the Average Variance Extracted (AVE) is the ability to calculate the variation interpretation of each observable variable by the non-observable (hidden) variant, and If the AVE value is higher, the implicit variable / unobservable variable has higher reliability and convergent validity.

Typically, Usually the AVE value must be greater than 0.5 , which means that the explainable variation from the observable variable is greater than the measurement error. The AVE in this study is greater than 0.5, which indicates that the observable variables / Explicit Variables have a high reliability and convergent validity (Tables 2 \& Figure 2).

Table 2: Judgment indexes of the measurement system in the model

\begin{tabular}{|c|c|c|c|}
\hline \multirow{2}{*}{ Latent/Implicit Variables } & $\begin{array}{c}\text { Observable variable } \\
\text {-Centralized double } \\
\text { measurement }\end{array}$ & $\begin{array}{c}\text { Factor } \\
\text { loading }\end{array}$ & $\begin{array}{c}\text { Average Variance } \\
\text { Extracted, AVE }\end{array}$ \\
\hline $\begin{array}{c}\text { Product Planning and Design } \\
(\mathrm{PD})\end{array}$ & $\mathrm{PD}_{1} \mathrm{C}$ & .851 & .661 \\
\cline { 2 - 4 } & $\mathrm{PD}_{2} \mathrm{C}$ & .832 & .653 \\
\hline $\begin{array}{c}\text { Macro Environmental } \\
\text { Factors (ME) }\end{array}$ & $\mathrm{ME}_{1} \mathrm{C}$ & .812 & .641 \\
\cline { 2 - 4 } & $\mathrm{ME}_{2} \mathrm{C}$ & .823 & .623 \\
\hline \multirow{2}{*}{$\mathrm{PD} \mathrm{ME}$} & $\mathrm{PD}_{1} \mathrm{ME}_{1} \mathrm{C}$ & .872 & .681 \\
\cline { 2 - 4 } & $\mathrm{PD}_{2} \mathrm{ME}_{2} \mathrm{C}$ & .854 & .664 \\
\hline
\end{tabular}

\section{Un-Standardized Results of SEM Analysis}

The Un-Standardized) results using computer software (M plus) is shown in Figure 2.
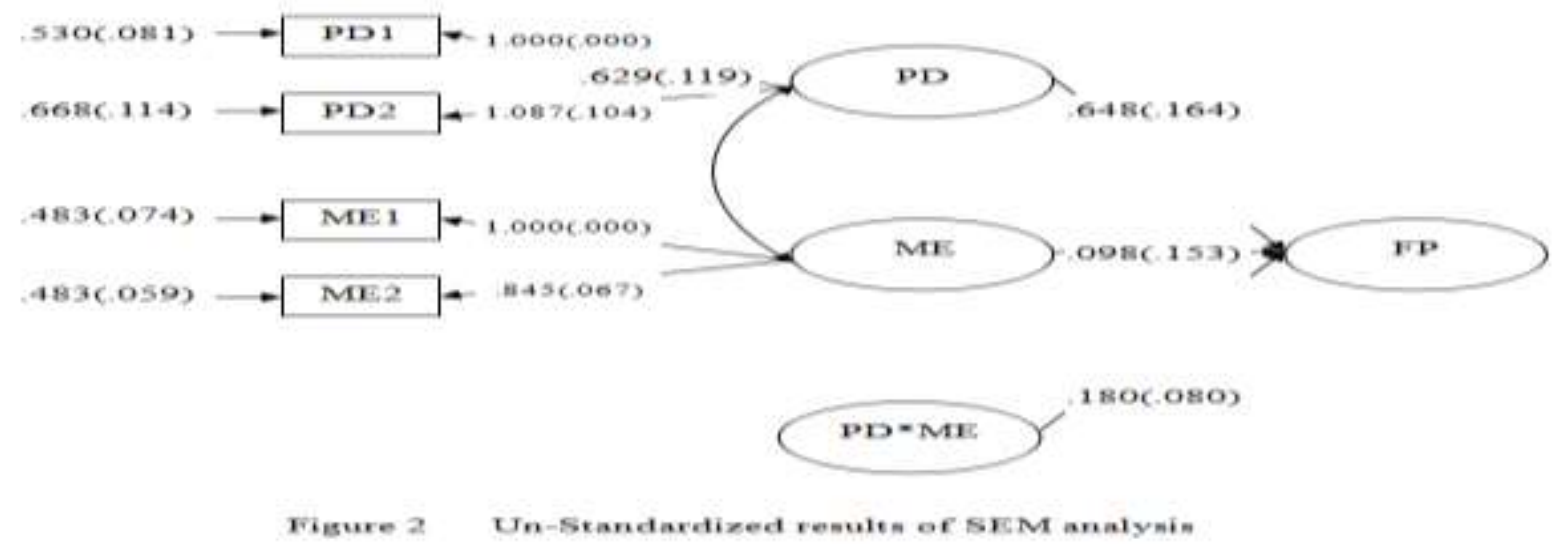


\section{Path-Effect-Analysis and Verification of Structural model}

The verification of intervening variable in this study is to firstly perform Hierarchical Regression (see Tables 3\& 4), and then perform regression analysis of $\mathrm{PD}, \mathrm{ME}$, $\mathrm{PD}^{*} \mathrm{ME}$ on FP (centralized) to test the significance of the partial regression coefficient $\mathrm{c}$ whether it is true or not, that is, whether c is equal to zero as shown in Table 5. The so-called coefficient of determination is also called Squared Multiple Correlation (SMC), that is, the degree of interpretation of the "independent variable" of each potential variable to the "dependent variable" of each potential variable.

Table 3: Hierarchical Regression

\begin{tabular}{|c|c|c|c|c|c|c|c|c|c|}
\hline \multirow[b]{2}{*}{ Model } & \multirow[b]{2}{*}{$\mathbf{R}$} & \multirow[b]{2}{*}{$\begin{array}{c}\mathbf{R} \\
\text { Square }\end{array}$} & \multirow[b]{2}{*}{$\begin{array}{l}\text { Adjusted } \\
\text { R Square }\end{array}$} & \multirow{2}{*}{$\begin{array}{l}\text { Std. Error } \\
\text { of the } \\
\text { Estimate }\end{array}$} & \multicolumn{5}{|c|}{ Change Statistics } \\
\hline & & & & & $\begin{array}{c}\text { R Square } \\
\text { Change }\end{array}$ & F Change & df1 & df2 & $\begin{array}{l}\text { Sig. F } \\
\text { Change }\end{array}$ \\
\hline 1 & $.872^{\mathrm{a}}$ & .761 & .752 & .31 & .009 & 179.221 & 2 & 97 & .001 \\
\hline 2 & $.881^{\mathrm{b}}$ & .771 & .761 & .41 & .010 & 7.022 & 1 & 96 & .001 \\
\hline
\end{tabular}

Note: (a) Predictors: (Constant), ME and PD; (b) Predictors: (Constant), ME, PD and ME*PD

Table 4 Coefficients of Determination

\begin{tabular}{|c|c|}
\hline Coefficients of Determination & $\mathbf{R}^{2}$ \\
\hline Product Planning and Design (PD), Macro Environmental Factors (ME) to Financial \\
Performance (FP) & .761 \\
\hline Product Planning and Design (PD), Macro Environmental Factors (ME), and PD-ME on & .771 \\
\hline
\end{tabular}

Note: Table 4 was taken from Table 3.

Table 5: Model Results

\begin{tabular}{|c|c|c|c|c|c|c|}
\hline & & & & & & Two-Tailed \\
\hline & & & Estimate & S. E. & Es t. /S.E. & P-Value \\
\hline & & BY & & & & \\
\hline & PD1 & & 1.000 & 0.000 & 999.000 & 999.000 \\
\hline ME & & & 1.087 & 0.677 & 1.606 & 0.124 \\
\hline & ME1 & & 1.000 & 0.000 & 999.000 & 999.000 \\
\hline & ME2 & & 0.993 & 0.631 & 1.098 & 0.211 \\
\hline FP & & ON & & & & \\
\hline & PD & & 0.036 & 0.053 & 0.672 & 0.313 \\
\hline & ME & & 0.045 & 0.063 & 0.714 & 0.302 \\
\hline & PD*ME & & 0.081 & 0.061 & 1.333 & 0.243 \\
\hline ME & & WITH & & & & \\
\hline & PD & & 0.477 & 0.088 & 5.417 & 0.000 \\
\hline
\end{tabular}

Source: This study. Note: $\mathrm{P}<0.05$ indicates the existence of interaction;

From Table 5, the following verification results can be found in this study as below.

- Product Planning and Design (PD) has a positive impact on Financial Performance (FP), but not significant, and its un-standardized path factor is .036, so it is assumed that $\mathrm{H}_{1}$ is partially supported. (The hypothesis is partially established)

- The Macro environmental factor (ME) has a positive impact on financial performance (FP), but is not significant, and its un-standardized path factor is .045 , so it is 
assumed that $\mathrm{H}_{2}$ is partially supported. (The hypothesis is partially established)

- Product Planning and Design (PD) and Macro Environmental Factors (ME), both of which have a positive interactive effect on Financial Performance (FP), but are not significant, with an un-standardized path factor of .081 , so it is assumed that $\mathrm{H}_{3}$ is partially supported. (The hypothesis is partially established)

\section{The Indices of Fit of the Overall SEM}

\section{Model}

The established SEM model in this study aims to verify the relationship between

observable variables in Structural models, and whether the measurement system has a measure of reliability and the fitting-effect of the Overall SEM model, while measuring the overall allocation of moderate indicators in this study are $X^{2}$, d. f., GFI, AGFI, NFI, CFI, RMR, RMSEA etc.; usually at $X^{2 / d}$. f. $<5 ; 1>$ GFI $>0.9 ; 1>$ NFI $>0.9 ; 1>$ CFI $>0.9 ; \mathrm{RMR}<0.05$; RMSEA $<0.05$ [18]; the Overall model of this study is moderate to " $\mathrm{x} 2 / \mathrm{d}$. $\mathrm{f}$. $<5$ " ; in addition, GFI, AGFI, and NFI are all greater than 0.90, while RMR values are less than 0.05 , indicating that the overall fit of this study model fits well (goodness-of-fit), as shown in Table 6.

Table 6: The overall model is appropriate for the degree scale

\begin{tabular}{|l|l|l|l|l|l|l|l|l|}
\hline $\begin{array}{l}\text { Determination } \\
\text { index }\end{array}$ & $\mathrm{X}^{\mathbf{2}}$ & $\mathbf{D F}$ & GFI & AGFI & NFI & CFI & RMR & RMSEA \\
\hline Fit value & 12.71 & 14 & 0.92 & 0.91 & 0.90 & 0.90 & 0.00 & 0.00 \\
\hline
\end{tabular}

Source: this study

\section{Conclusions and Suggestions}

\section{Findings}

Through the above data analysis and results, the following specific conclusions can be obtained as below.

- In terms of model verification of SEM, the linear structural equation modeling (SEM) constructed by this study, and its Measurement Model, Structural Model and Overall model have a good fit-of-goodness, showing that this established model in this study fits well.

- For the validation of practice:

Product Planning and Design (PD) and Macro Environmental Factors (ME) of Taiwan publicly-listed construction companies have a positive interactive effect on Financial Performance (FP), but not significant (its un-standardized path factor is .081), which implies that Macro Environmental Factors (ME) play an important role in promoting
Financial Performance (FP).

I.e. Even though the companies have good capabilities of Product Planning and Design, but in the event of a harsh overall environment such as war or outbreaks of plagues and other force majority factors, their financial performance will be greatly affected; on the contrary, under good Macro environmental factors, once the companies have bad Product planning and design proposal, it will inevitably affect their sales volume and then affect the financial performance.

\section{Contribution to this Study}

- This study models SEM model in conjunction with the relevant research results of past scholars and then verifies that the model is appropriate to see if it has a good fit-of-goodness effect, so the subject of this study is the importance of Confirmatory Factor Analysis (CFA), so it is 
not only worthy of provide the follow-up researchers in this related field as references, the results of this study can also provide a very managerial reference value for the operators of the listed construction companies and decision makers of the government relevant sectors so this research results are practical.; and

- The main constructs of this research topic is non-observable variables /implicit variables, so it is more suitable to use Confirmatory factor analysis (CFA) and Linear Structure Equation Modeling (SEM) as measurement tools and model framework for this study, so this research method is more innovative of theoretical application.

\section{References}

1. He NX (2014) Discussion on the Relevance of Land Location and Product Planning. Taiwan: National Chung Cheng University Senior Executive Master's thesis.

2. Tay PK (2014) A Case Study on Product Planning: GIANT ANYROAD. Taiwan: Master's thesis of the Master's Program in the Industrial Product Design Department of Shih Chien University.

3. Huang HH (2019) Corporation Brand Building of Construction Company-A Case of LONGBAO Company. Taiwan: Master's thesis of the Department of Business Management, National Yunlin University of Technology.

4. MBA (2019) Product planning, source: https://wiki.mbalib.com/zh-tw/\%E4\%B A\%A7\%E5\%93\%81\%E8\%A7\%84\%E5\% $88 \% 92$

5. Chen HL (2016) the study of Key Success Factor of the Construction Company after Implementing New Regulation of Housing and Land Tax Unity-A Case study of Kaohsiung Area. Taiwan: Master's thesis of the Department of Business Administration, National Sun Yat-sen

\section{Research}

\section{Recommendations}

Limitations

and

This study is a "one independent variable on one dependent variable with one moderator" model, and is limited to the Confirmatory factor analysis (CFA) of the publicly-listed construction companies in Taiwan, and suggests that subsequent researchers may consider establishing different models, such as the "two independent variables on one dependent variable with one moderator" model and verifying the model-fit to see if the model has a fit-of-goodness effect and whether there is significant interaction /synergy effect happened or not.

\section{University.}

6. Lin YT, Hong KH (1997) Pre-operation strategy for construction case. Taiwan: Baochuan Publishing House.

7. Zhang JE (2003) Real Estate Investment and Market Analysis Theory and Practice. Taiwan: Huatai Cultural Business.

8. Situ DX (1979) Environmental Analysis of Taiwanese Enterprises. Taiwan: Corporate Banking Quarterly, 3(1).

9. Pearce, Robinson (2000) Formulation, Implementation, and Control of Competitive Strategy. (7th ed). Boston: McGraw-Hill Irwin.

10. Hong MZ (1997) Management: Cases, Theory, Dialectics. Taipei: Science and Technology Book Publishing Company.

11. Kaplan RS, DP Norton (1992) the Balanced Scorecard: Measures that Drive Performance. Harvard Business Review, 70(1):71-79.

12. Lii JY (2004) Research the Enterprise Flow Internal Performance Evaluation Indicators Establishment-Take the Systems Science Theory as the Discussion. Taiwan: Master's thesis of the Institute of 
Enterprise Management, Chung Yuan National Culture University.

13. Khaliun Bibish (2015) A Comparison of Financial Performance of Food Companies in Mongolia by Using Financial Ratio Analysis. Taiwan: Department of Tropical Agriculture and International Cooperation, National Pingtung University of Science and Technology.

14.Xie BE (2018) The Relationship between Financial Performance and Stock Return-Empirical Evidence from the Public-Listed Companies of Taiwan 50 index as an example. Taiwan: Master's thesis of Adult Education Institute of National Kaohsiung Normal University.

15. Chen YC (2018) the Impact of Corporate Social Responsibility on Corporate Firm Performance- A Case Study of Taiwanese Companies.
Taiwan: Master's thesis of the Department of Business Administration, Asia University.

16. Diamantopoulos Adamantios, Judy A Siguaw (2000) Introducing LISREL: A Guide for them. Uninitiated. London: Sage Publications.

17. Fornell C, Larcker DF (1981) Evaluating structural equation models with un-observables and measurement error. Journal of Marketing Research, 18: 39-50.

18. Bagozzi RP, Yi Y (1988) on the evaluation of structural equation models. Academy of Marketing Science. Journal. 16(1):74-94.

19. Taiwan Economic News Database (2019) search URL: https://www.tej.com.tw/twsite/TEJ\%E8\%B 3\%87\%E6\%96\%99\%E5\%BA\%AB/tabid/164 /language/zh-TW/Default.aspx 